\title{
WOUND HEALING AND ANTI INFLAMMATORY EFFECTS OF PROPOLIS IN CRITICAL SIZE DEFECT OF RAT BUCCAL MUCOSA (HISTOCHEMICAL AND IMMUNO HISTOCHEMICAL STUDY)
}

\author{
Samah Mohamed Kamel*, Mohamed Abdel Salam El Baz Younis ${ }^{* *}$ and Reham A.A. Morsy ${ }^{* * *}$
}

\begin{abstract}
Objectives: the aim of this study is to evaluate the healing and anti-inflammatory effects of propolis in critical wound defects in rats ' buccal mucosa.

Subjects\& methods: 20 adult male albino rats of average weight 150-250 grams were used. Rats were divided into 2 groups

Group I: consists of 10 rats, which were subdivided into 2 sub groups

Sub Group I A: consists of 5 rats, the wounds were left un treated for 3 days

Sub Group I B: consists of 5 rats, the wounds were left un treated for 7 days

Group II: Consists of 10 rats which were subdivided into 2 sub groups

Sub Group II A: consists of 5 rats, the wounds were treated with propolis for 3 days

Sub Group II B: consists of 5 rats, the wounds were treated with propolis for 7 days

The wounds were examined histologically, histochemically and immunohistochemically

Results: Histologiacally, histochemical and immunohistochemical results showed that the healing process was faster in propolis treated rats due to anti inflammatory and anti oxidant effects of Propolis. Immunohistochemical labeling of vimentin in propolis treated groups was higher than un treated groups

Conclusion: Propolis could improve wound healing by stimulating the proliferation of epithelial cells; and fibroblast proliferation, thus improving wound closure and decreasing inflammation (as prolonged inflammation and the release of inflammatory cytokines could cause tissue damage)
\end{abstract}

KEY WORDS: wound healing , anti inflammatory, Propolis, Vimentin

\footnotetext{
* Lecturer, Department of Oral Biology, Faculty of Dentistry, October University of Modern Sciences and Art

** Lecturer, Department of Oral and Maxillofacial Surgery, Faculty of Dentistry, October University of Modern Sciences and Art.

***Assoc Prof Basic Dental Science Department NRC
} 


\section{INTRODUCTION}

Wound healing results from a complicated process of tissue repair to displace devitalized and missing cell structures and layers of tissue. This process is divided into four highly programmed stages: blood coagulation, inflammation, new tissue growth (proliferation) and tissue remodeling (maturation). ${ }^{(1)}$ There are complex and coordinated chain of events in these phases that include chemotaxis, phagocytosis, neocollagenesis, collagen degradation, and collagen remodeling in addition to angiogenesis, epithelization, and the production of new glycosaminoglycans and proteoglycans ${ }^{(2,3)}$.

It is technically difficult to manage certain complicated wounds, such as diabetic, chronic, infected, burnt and large wound defects. The cure of these wounds is a difficult situation and enters a state of pathological inflammation due to a postponed, incomplete or uncoordinated cure process. ${ }^{(4,5)}$

Pro-inflammatory cytokine IL-1 $\quad$,IL-6and TNF- $\alpha$ are released early in the wound healing process by immune cells and influence keratinocytes and fibroblasts to stimulate tissue deposition and epithelization $^{(6,7)}$. Persistent inflammation was directly linked to delayed healing and wound chronicity $^{(8)}$, high levels of these cytokines are found in complicated wounds that lead to fibroblast apoptosis and extracellular degradation of the matrix. ${ }^{(9)}$.

Vimentin has developed in many different tissues and cell types as a critical regulator for the wound healing process. This protein has been shown to serve as a signaling integrator for tissue regeneration and cure ${ }^{(10)}$. Vimentin is a defining feature of a resident mesenchymal "repair" cell population, located in niches in the cells of the epithelium of the lens equatorial. This mesenchymal cell population is activated on wounding to immediately migrate to and populate the leading edge of the injured epithelium. ${ }^{(11,12)}$
The proper tensile strength and biomechanical properties of wounds depend on the biochemical composition of the wound during the late remodeling phases of the healing process and are primarily controlled by the collagen typeI deposited in the extracellular matrix and the balance between MMPs and their tissue inhibitors. ${ }^{(13,14)}$. Type I collagen, an important extracellular matrix, not only gives the tissue matrix strength and integrity, but also plays an important role in homeostasis and epithelization during wound healing. ${ }^{(15)}$

Reduced collagen deposition was reported as a delayed wound healing mechanism as shown by low levels of hydroxyproline in the presence of normal collagenase activity in complicated wounds ${ }^{(16)}$. Increased levels of collagen type III compared to collagen type I also affect the delayed wound healing (17). During wound healing, the presence of MMPs is required early to stimulate the mobilization of keratinocytes and to activate the precursors of different inflammatory mediators and growth factors ${ }^{(14)}$. Excessive and prolonged expression of MMP in later stages of wound healing is detrimental ${ }^{(18)}$

When TGF- $\beta$ ligand binds to serine / threonin receptors, the kinase activity Smad 2 and Smad 3 become phosphorylated, causing them to bind to Smad 4 and move to the nucleus, where they control the expression of TGF- $\beta$ target genes. ${ }^{(19)}$. TGF- $\beta$ is responsible for the chemotaxis of inflammatory and immune cells to the wound site and also stimulates extracellular matrix deposition and granulation tissue formation. TGF- $\beta$ supports the epithelization of wounds by stimulating keratinocyte proliferation. ${ }^{(20)}$

Propolis is a natural honeybee product (bee glue). The extract is a complicated natural mixture of substances. It includes amino acids, phenolic acids, esters of phenolic acid, flavonoids, cinnamic acid and caffeic acid. Propolis has various biological and pharmacological properties; antibacterial, antifungal, anti-inflammatory, antioxidant, immunomodulatory, antiviral and anti-carcinogenic. ${ }^{(21,22)}$ 
The use of propolis dates back to ancient times, at least $300 \mathrm{BC}$, and was used in many parts of the world as a medicine for internal and external uses. The use of propolis for its general healing qualities was reported by Egyptians, Greeks and Romans. Ancient Egyptians used it to embalm their dead. It was later used in healing during the Boer War ${ }^{(23)}$. Propolis has been used empirically for centuries and it has several biological applications including acceleration of regenerating processes in the damaged cartilages and bones ${ }^{(24)}$, Since propolis has these various biological properties, the aim of this study is to evaluate the healing and antiinflammatory effects of propolis in critical wound defects in rats ' buccal mucosa.

\section{MATERIALS AND METHODS}

\section{Chemicals}

Raw propolis: it was bought from the beekeeper who collects these resinous materials by scraping from bee hives. They put them in the refrigerator until they get hard enough to powder. A sample of propolis extract has been prepared and used in this study, as described by Bogdanov ${ }^{(25)}$.The propolis powder was extracted with $80 \%$ ethanol $(30 \%$ propolis solution was used). This mixture was allowed to stand for 10 days at room temperature, with periodic agitation several times each day. At the end of 10 days, the mixture was filtered through filter paper. For the base of the cream, Vaseline and lanolin in a proportion of 9:1 was used. For $100 \mathrm{~g}$ of this base, $20 \mathrm{ml}$ of $30 \%$ propolis ethanol extract was used for preparation of $6 \%$ propolis cream. Then, warming up of the base in a water bath (at about $40-50^{\circ} \mathrm{C}$ ) and adding propolis extract were performed. While stirring, evaporation of ethanol was performed by boiling. Thereafter, the warm cream was sieved and packed in a dark, tightly closed cream box.

This mixture was allowed to stand at room temperature for 10 days, with periodic agitation several times a day. The mixture was filtered through filter paper at the end of the 10 days. Vaseline and lanolin in a proportion of 9:1 were used for the base of the cream. For $100 \mathrm{~g}$ of this base, $20 \mathrm{ml}$ of $30 \%$ ethanol propolis extract has been used to prepare $6 \%$ propolis cream. Then, the base was heated in a water bath (at about $40-50{ }^{\circ} \mathrm{C}$ ) and the propolis extract was added. Evaporation of ethanol was performed by boiling while stirring. The warm cream was then sieved and packed into a dark, tightly closed cream box.

\section{Animals}

20 adult male albino rats of average weight 150-250 grams were used from the Animal House (Faculty of Medicine, Cairo University, Egypt). Rats were housed in stainless-steel cages, 5 rats per cage. All rats were maintained on basic diet of regular rat chow and distilled water adlibitum. Rats were divided into 2 groups

Group I: consists of 10 rats, which were subdivided into 2 sub groups

Sub Group I A: consists of 5 rats, the wounds were left un treated for 3 days

Sub Group I B: consists of 5 rats, the wounds were left un treated for 7 days

Group II: Consists of 10 rats which were subdivided into 2 sub groups

Sub Group II A: consists of 5 rats, the wounds were treated with propolis for 3 days

Sub Group II B: consists of 5 rats, the wounds were treated with propolis for 7 days

\section{Rat excision wound model}

All animals were anesthetized through intramuscular injection with a mixture of $13 \mathrm{mg} / \mathrm{kg}$ xylazine (2 percent) and $33 \mathrm{mg} / \mathrm{kg}$ ketamine. The cheek was pulled after anesthesia and a wound was induced opposite the premolar area using a sterile punch biopsy instrument (4 $\mathrm{mm}$ diameter) limited to mucosal tissues. 
All wounds were left undressed and were cleaned daily with normal saline in all the groups. The wounds in group II were treated with propolis cream, topically once daily after cleaning for a period of 3 days and 7 days

\section{Sample collection}

After 3 and 7 days of treatment the animals were euthanized with cervical dislocation. The buccal mucosa containing the wound induced has been dissected. Each wound was excised and about $2 \mathrm{~mm}$ of intact mucosa was maintained around the marked lesion. Then fixed in a solution of 10 percent formalin and submitted to routine laboratory studies after sectioning with a thickness of $4 \mu$. Samples were stained with hematoxyline and eosin, Toluidine blue for the detection of mast cells that should stain red-purple, and immunohistochemically tested with Vimentin. This monoclonal antibody reacts with the intermediate filament protein in mesenchymal cells.

\section{Histomorphometric analysis:}

Using the image analyzer computer system ( Leica Qwin 500C; Leica, England, UK). Inflammatory cells were counted in H\&E sections. In addition, the intensity of Vimentin immune expression in highpower non- overlapping fields was measured.

\section{Statistical analysis:}

Data were presented as Mean, Standard deviation (SD) values. Data were explored for normality using Kolmogorov-Smirnov and Shapiro-Wilk tests. Values of inflammatory cell counts followed normal distribution, while those of Vimentin area weren't normally distributed so a log transformation was made to allow the use of parametric tests for the analysis. One-way ANOVA test followed by Tukey's post hoc test was used for the statistical analysis. The significance level was set at $\mathrm{P} \leq 0.05$. Statistical analysis was performed with IBM®
SPSS® Statistics Version 25 for Windows.

\section{RESULTS}

\section{Histological results}

Regarding H\&E stain evaluation, it was found that After 3 days, sub group IA showed incomplete epithelial rim covering the wound lesion. The sub epithelial connective tissue showed numerous scattered inflammatory cell infiltrations. While in sub group II A the newly formed epithelial lining appeared in a form of thin continuous layer of basal and parabasal cells that cover all the wound lesion with less inflammatory cell infiltrates in the underlying connective tissue was observed. After 7 days, the newly formed covering epithelium in the sub group IB is continuous and thin. The subepithelial connective tissue revealed some inflammatory cells. In sub group IIB, the wound was completely covered with hyperkeratotic acanthotic epithelium. The subepithelial connective tissue in showed fewer inflammatory cells compared to the sub group IB (Fig. 1)

\section{Histolochemical results}

Regarding Tolouidine blue stain evaluation, it was found that After 3 days, sub group IA showed numerous sub epithelial mast cells while sub group II A showed less number of mast cells. After 7 days sub group II B showed very few number while sub group I B still has large number of mast cells (Fig 2)

\section{Immuno-histolochemical results}

Immunohistochemical labeling of vimentin in sub groups II A and B is very high resulting in re epithelization, fibroblast proliferation and collagen formation while less immunohistochemical labeling of vimentin in sub groups I A and B as a result of that the rate of wound healing is slower. (Fig 3) 


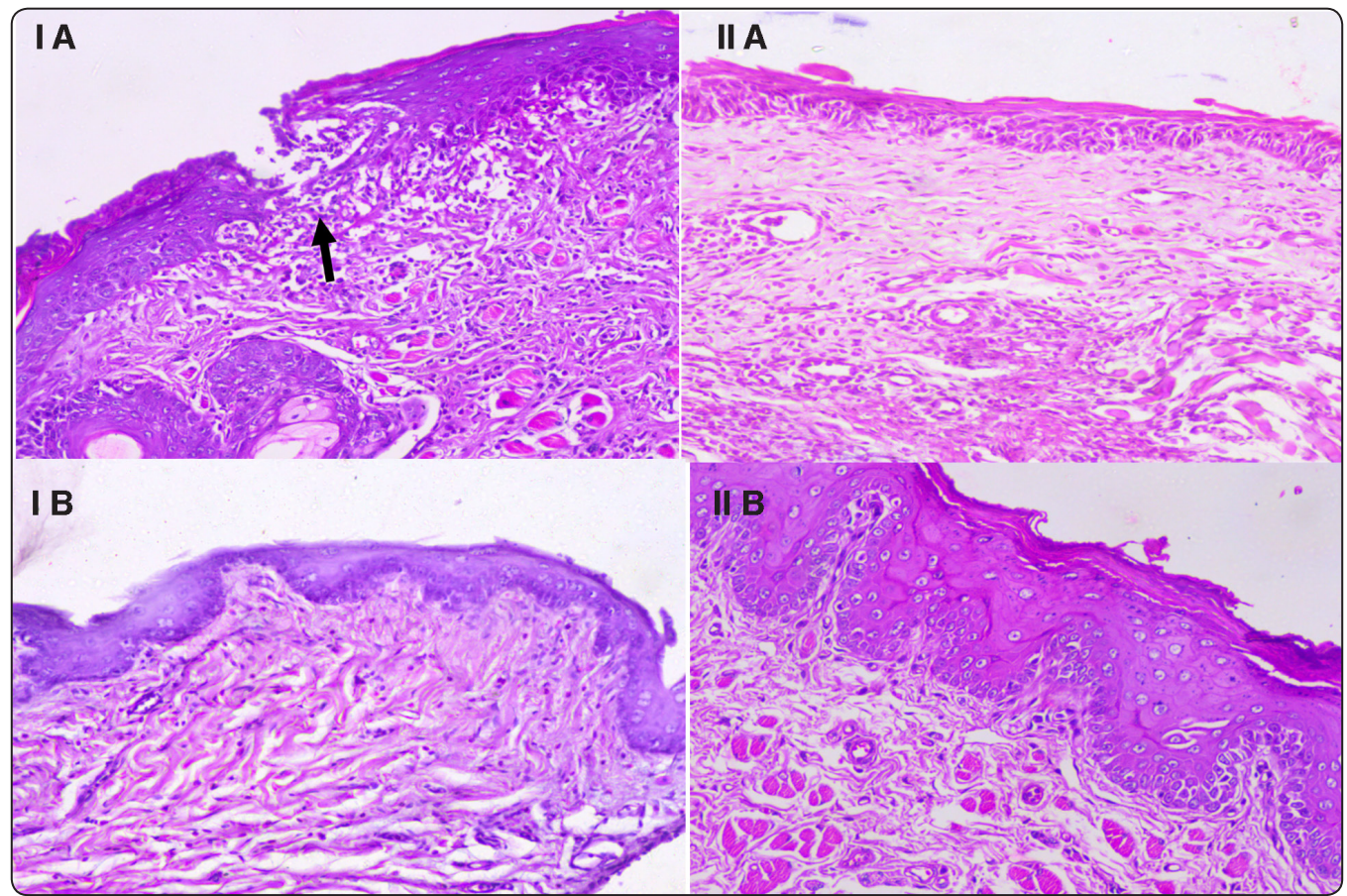

Fig. (1) Photomicrographs of the histologic section of the wounds. After 3 days the epithelium of the sub group IA is incomplete rim of basal and parabasal cells numerous scattered inflammatory cells(black arrows). While In the sub group IIA epithelium is continuous epithelium, after 7 days. All wounds were covered with epithelium sub group IB showing continuous proliferating epithelium with irregular rete pegs and some inflammatory cells in the underlying lamina propria. sub group IIB showing hyperkeratotic and acanthotic epithelium. (200x)

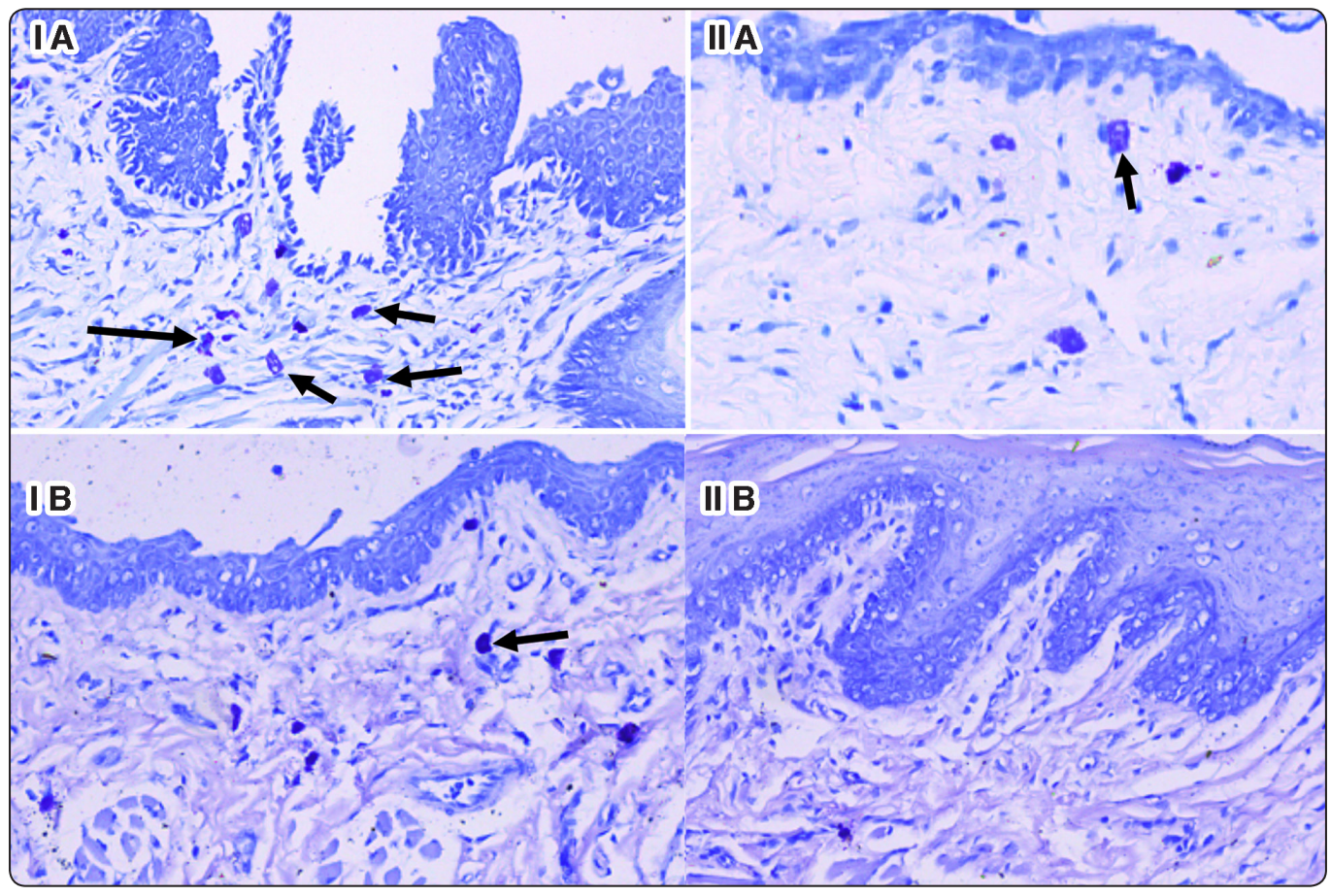

Fig. (2) Photomicrographs of the histologic section of the wounds. After 3 days the sub group IA has numerous scattered mast cells(black arrows).While In the sub group IIA less number of mast cells, after 7 days. sub group IB showing some mast cells in the underlying lamina propria. sub group IIB very few number of mast cells. (200x). 


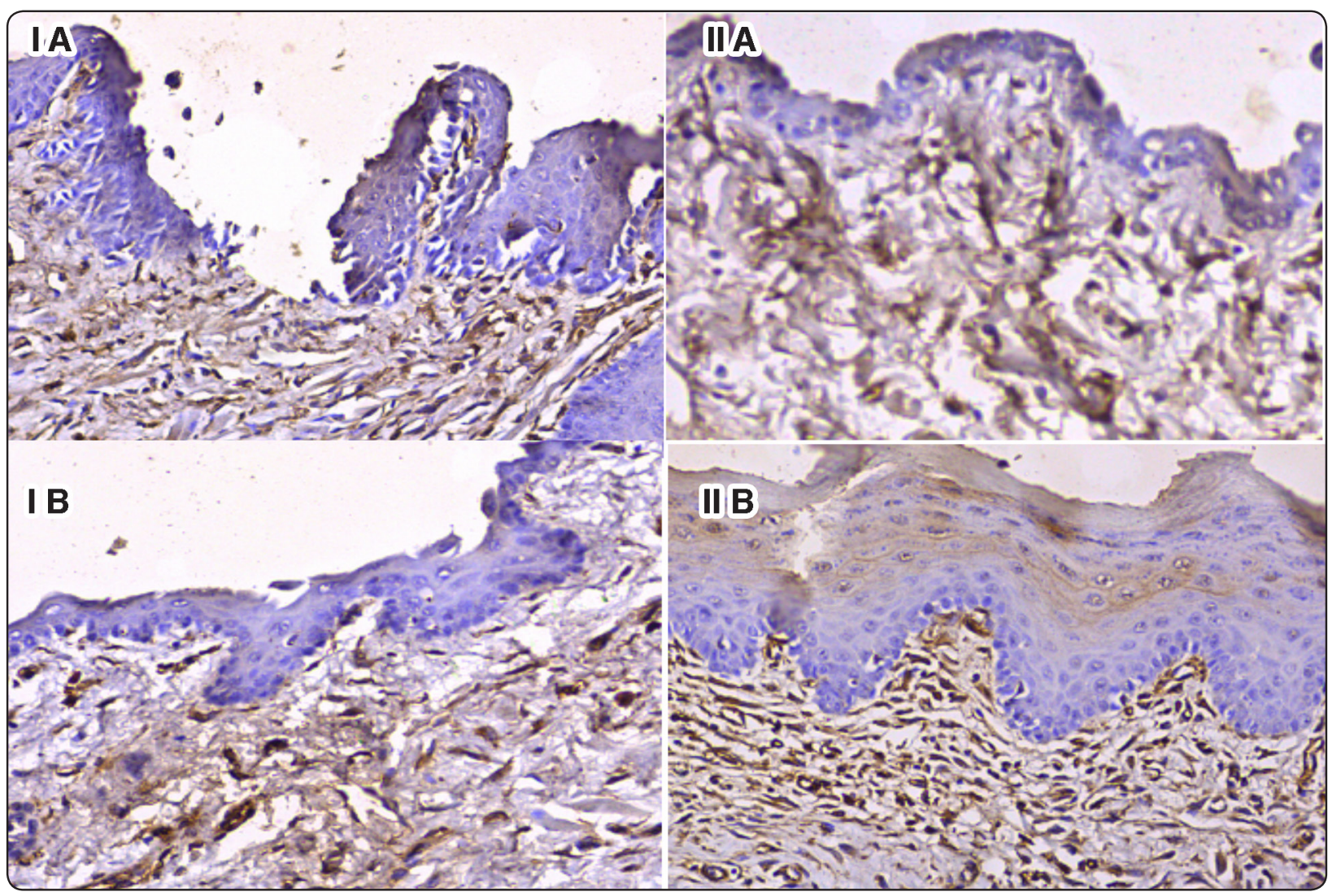

Fig. (3) Photomicrographs showing that immunohistochemical labeling of vimentin in sub groups II A and B is very high resulting in re epithelization and collagen formation while less immunohistochemical labeling of vimentin in sub groups I A and B . (200x).

\section{Histo morphometrical and statistical results}

Mean, Standard deviation (SD) values of bacterial cell count and $\log$ transformation of the area of Vimentin $\left(\mathrm{pp}^{2}\right)$ for different subgroups were presented in table (1) and figures $(4,5)$

\section{Inflammatory cell count}

There was a significant difference between the count of inflammatory cells in different subgroups $(\mathrm{P}<0.001)$. The highest $($ mean $\pm \mathrm{SD})$ value was found in subgroup (IA) $(96.40 \pm 10.21)$, followed by sub groups (IIA) (49.40 \pm 7.50$)$ and (IB) $(40.20 \pm 9.57)$ while the lowest value was found in (IIB) $(20.40 \pm 4.87)$. Pairwise comparison showed bacterial cell count of subgroups (IB) and (IIA) to be significantly different from that of other subgroups $(\mathrm{P}<0.001)$.

\section{Vimentin area}

There was a significant difference between the area of Vimentin in different groups $(\mathrm{P}<0.001)$. The highest $($ mean $\pm \mathrm{SD})$ value was found in subgroup (IIB) $(5.12 \pm 0.01)$, followed by sub groups (IB) $(5.06 \pm 0.03)$ and (IIA) $(4.84 \pm 0.005)$ while the lowest value was found in (IA) $(4.71 \pm 0.02)$. Pairwise comparison showed subgroups (IB) and (IIB) to be significantly different from other subgroups $(\mathrm{P}<0.001)$. 
TABLE (1): Mean, Standard deviation (SD) values of bacterial cell count and log transformation of the area of Vimentin (pp2) for different subgroups

\begin{tabular}{cccccc}
\hline \multicolumn{5}{c}{ Groups $($ mean \pm SD $)$} \\
\hline Parameter & $($ IA $)$ & $($ IB $)$ & $($ IIA $)$ & $($ IIB $)$ & P-value \\
\hline $\begin{array}{c}\text { Inflammatory cell } \\
\text { count }\end{array}$ & $96.40 \pm 10.21^{\mathrm{A}}$ & $40.20 \pm 9.57^{\mathrm{B}}$ & $49.40 \pm 7.50^{\mathrm{B}}$ & $20.40 \pm 4.87^{\mathrm{C}}$ & $\mathrm{P}<0.001^{*}$ \\
\hline Vimentin area & $4.71 \pm 0.02^{\mathrm{C}}$ & $5.06 \pm 0.03^{\mathrm{A}}$ & $4.84 \pm 0.005^{\mathrm{B}}$ & $5.12 \pm 0.01^{\mathrm{A}}$ & $\mathrm{P}<0.001^{*}$ \\
\hline
\end{tabular}

Different superscript letters indicate a statistically significant difference between means within the same row. *; Significant at $(p \leq 0.05)$.

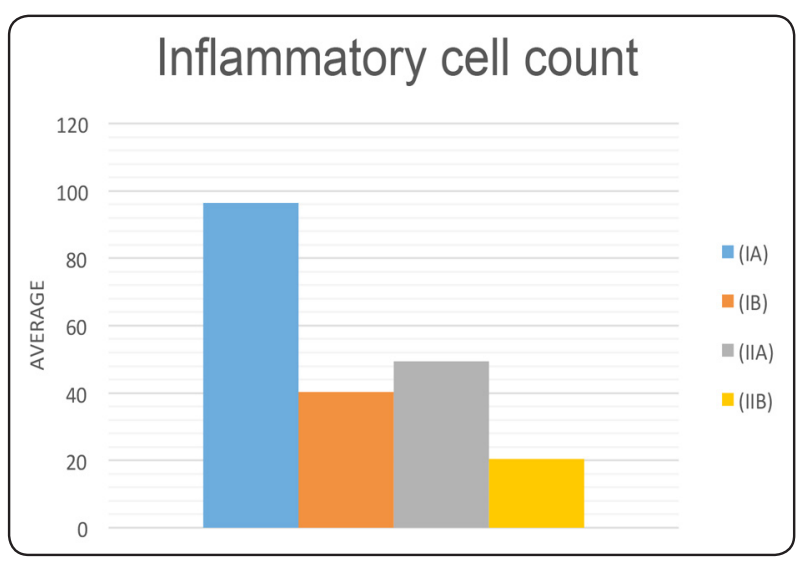

Fig (4): Bar chart showing average inflammatory cell count for different subgroups

\section{DISCUSSION}

Wound healing is a complex process involving the interaction of different cell types in the injured tissue, including inflammatory cells, keratinocytes, fibroblasts and endothelial cells. ${ }^{(26)}$ Wound healing is a natural reaction of the body that starts promptly after injury and takes place in four stages, including coagulation, inflammation, re- epithelization and remodeling. (27)

Since non-healing wounds are a big and growing problem, several treatments have been applied to improve the healing of wounds, but many of them did not cause any response in the wounds. Therefore, there is an ongoing need to develop agents that speed up the cure of acute and chronic injuries and ulcers and regenerate damaged tissue.

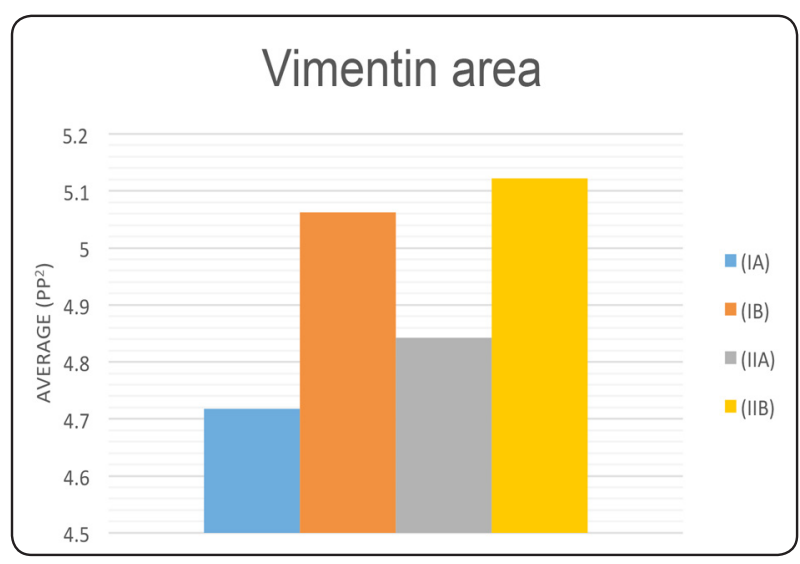

Fig. (5): Bar chart showing average Vimentin area (pp2) for different subgroups

The ideal topical wound treatment product must be biocompatible, non-toxic and can improve healing without adverse effects on the advancement of the natural wound healing process. ${ }^{(28)}$

The aim of this study was to evaluate Propolis healing potential as a topical treatment method for surgically induced wound on the buccal mucosa of rats. In the current study rats are commonly used in relation to other animals because of their low cost, easy manipulation and similarity between the oral mucosa of rats and humans; the oral epithelium of rats is essentially composed of surface epithelial tissue and subjacent connective tissue ${ }^{(29)}$.

Propolis has attracted the interest of researchers in recent decades due to various biological and pharmacological properties. Propolis is therefore 
a natural product with useful biological properties and no side effects recorded. Regarding the chemical composition of propolis used in this study, flavonoids were the main components of propolis which greatly contribute to the pharmacological activities of propolis. Flavonoids have a wide variety of biological activities, including anti-inflammatory, antibacterial and anti-viral effects. In addition, the propolis used contained phenylpropanoids, terpenoids, stilbenes, lignans, coumarins and their derivatives. Terpenoids accounted for $10 \%$ of the propolis and have antioxidant and antimicrobial effects. In addition, the propolis used contained large amounts of caffeic acid phenethyl ester (CAPE), 3-methylbut-2-enyl caffeate, isopentyl ferulate and moronic $\operatorname{acid}^{(30,31)}$.

The current study evaluated the healing process three and seven days after the induction of the wound. Literature reviews indicate that these time slots were the most commonly used to monitor tissue changes during wound healing ${ }^{(32,33)}$.

Histological examination of the specimens of subgroup I A Three days after wound induction revealed the infiltration of heavy inflammatory cells in the sub-epithelial connective tissues. These results have been in line with Hashemipour et al's work. ${ }^{(33)}$ where the polymorphonuclear leucocyte (PMNL) cell infiltrates recorded the highest inflammation score in the control group on the second day.

In the present study, the histological examination of the propolis-treated wound lesion showed less inflammatory cells in the connective tissue under the wound after three days. Since Propolis has different anti-inflammatory substances that suppress the synthesis of prostaglandins and leukotrienes and the activity of myeloperoxidase, NADPH-oxidase, ornithine decarboxylase and tyrosine protein kinase (34-36). These findings were in agreement with Martin et al ${ }^{(37)}$ who reported few neutrophils within 24 and 48 hours in response to silver nitrate-induced corneal ulcer in rats that were topically treated with Brazilian propolis with one percent micro-emulsion.
Seven days after wound induction, subgroup I B healing was obtained by epithelium regeneration; wounds were covered with a thin epithelium layer. The intensive inflammation of the underlying lamina propria decreased with the presence of few inflammatory cells. These results were consistent with Fahim et al. ${ }^{(38)}$ who created a circular wound of $3.0 \mathrm{~mm}$ diameter on the buccal mucosa of rats. On post-wound day 7 , they observed a significant increase in the thickness of the regenerating epithelium with fibroblasts, collagen fibers, blood vessels and inflammatory cells in the underlying lamina propria.

Various degenerative processes and diseases have involved oxidative stress. Propolis had antioxidant properties, mainly depending on the flavonoid content. It also induced antioxidant enzymes like catalase and superoxide dismutase to be activated against free radicals ${ }^{(39)}$. Flavonoids in propolis are potent antioxidants, capable of scavenging free radicals and thus protecting the cell membrane from lipid peroxidation, which helps in wound healing ${ }^{(40,41)}$.

Histological samples of propolis showed the closure of the wound with a reorganized epithelial layer in which epithelial cells showed a few mitotic figures in the present study after 7 days. The presence of fibroblasts and organized collagen fibers in the completely reconstructed lamina proporia with less inflammatory cells was recognized. According to these findings, propolis stimulates cell proliferation and tissue repair. These results were supported by Berretta et al. ${ }^{(42)}$ who used puncture wounded skin wistar rats to evaluate the propolis wound healing properties. Seven days after the injury, they reported epithelization, and the collagen fibers were completely reconstituted.

In the current study by counting the subepithelial inflammatory cells we found that there was a significant difference between the count of inflammatory cells in different subgroups $(\mathrm{P}<0.001)$. 
The highest (mean \pm SD) value was found in subgroup (IA) $(96.40 \pm 10.21)$, followed by sub groups (IIA) $(49.40 \pm 7.50)$ and (IB) $(40.20 \pm 9.57)$ while the lowest value was found in (IIB) $(20.40 \pm 4.87)$. Pairwise comparison showed bacterial cell count of subgroups (IB) and (IIA) to be significantly different from that of other subgroups $(\mathrm{P}<0.001)$.

In all phases of wound healing, mast cells play important roles. Mast cells accumulate at the wound edges after tissue injury and release vasoactive mediators such as histamine, proteases, tumor necrosis factor (TNF) and arachidonic acid metabolites ${ }^{(43-45)}$ which can cause vasodilation and enhance vascular permeability.

Propolis topical application can reduce the number of mast cells and this effect accelerates the healing process and has a high potential for wound healing. Propolis causes a significant reduction in mast cells in the surgical wound during the acute inflammatory phase, the phenethyl ester of caffeic acid and other active compounds in propolis may be responsible for this action. ${ }^{(46)}$. The phenethyl ester of caffeic acid is an active component of propolis and can reduce the release of histamine and the production of inflammatory cytokines in the healing tissue $^{(47,48)}$.

Histochemical examination of specimens in subgroup I A Three days after wound induction showed a higher number of mast cells in the subepithelial connective tissues than in subgroup II A, as propolis treatment affected the number of mast cells

After 7 days of propolis treatment, the number of mast cells decreased dramatically while the untreated wounds still had numerous sub-epithelial mast cells, these results were supported by a study conducted by Nader who found that IgE-induced immediate allergic reaction was attenuated by caffeic acid phenethyl ester. ${ }^{(48)}$

In this study, we have found that vimentin directly coordinates four cellular activities that are essential in controlling wound healing: proliferation of fibroblasts, collagen accumulation, trans-differentiation of keratinocytes and reepithelialisation. Many studies have shown that Vimentin-deficient wounds are noticeably collagenfree, apparently as a direct consequence of the severe inhibition of proliferation and expansion of fibroblast ${ }^{(49-51)}$. A study by Challa and Stefanovic showed that vimentin can contribute to the posttranscriptional regulation of collagen expression ${ }^{(52)}$

In the present study, Vimetin's expression in subgroup IIA was higher than in subgroup IA. Vimentin promotes proliferation of fibroblast, accumulation of collagen and re-epithelization. The wound was completely closed in subgroup IIA, while the wound was still not covered in subgroup I A, the healing process in subgroup II B was completed, as a result, the expression of Vimentin was increased. These results were supported by Chen et $\mathrm{al}^{(53)}$ Who stated that Vimentin coordinated fibroblast proliferation and keratinocyte differentiation in wound healing.

These findings were supported histomorphometrically and statistically as there was a significant difference between the area of Vimentin in different groups $(\mathrm{P}<0.001)$. The highest $($ mean $\pm \mathrm{SD})$ value was found in subgroup (IIB) $(5.12 \pm 0.01)$, followed by sub groups (IB) $(5.06 \pm 0.03)$ and (IIA) $(4.84 \pm 0.005)$ while the lowest value was found in (IA) $(4.71 \pm 0.02)$. Pairwise comparison showed subgroups (IB) and (IIB) to be significantly different from other subgroups $(\mathrm{P}<0.001)$.

\section{CONCLUSION}

Propolis could improve wound healing by stimulating the proliferation of epithelial cells; and fibroblast proliferation, thus improving wound closure and decreasing inflammation (as prolonged inflammation and the release of inflammatory cytokines could cause tissue damage). 


\section{REFERENCES}

1. Stavrou D. Neo vascularisation in wound healing. Journal of wound care; vol.17 , no.7,pp.298-300,2008.

2. Sgonc R and Gruber J. Age-related aspects of cutaneous wound healing: a minireview. Gerontology; 59:159-164, 2013.

3. Gantwerker EA and Hom DB. Skin: histology and physiology of wound healing. Clin Plast Surg; 39:85-97, 2012.

4. Datiashvili RO and Yueh JH. Management of complicated wounds of the extremities with scapular fascial free flaps, J. Reconstr. Microsurg; 28 (08) :521-528, 2012.

5. Hasan MY, Teo R, Nather A. Negative-pressure wound therapy for management of diabetic foot wounds: a review of the mechanism of action, clinical applications, and recent developments, Diabet. Foot Ankle 6 ;27618, 2015.

6. Park JE, Barbul A : Understanding the role of immune regulation in wound healing. Am J Surg; 187 :11S-16S, 2004.

7. Werner $\mathrm{S}$, Grose $\mathrm{R}$ : regulation of wound healing by growth factors and cytokines. Physiol Rev; 83:835-870, 2003.

8. Dinh T, Tecilazich F, Kafanas A, Doupis J, Ginardellis C, Leal E, Tellechea A, Pradhan L, Lyons TE, Giurini JM, Veves A: Mechanisms involved in the development and healing of diabetic foot ulceration. Diabetes; 61:29372947, 2012.

9. Siqueira MF, Li J, Chehab L, Desta T, Chino T, Krothpali N, Behl Y, Alikhani M, Yang J, Braasch C, Graves DT : Impaired wound healing in mouse models of diabetes is mediated by tnf-alpha dysregulation and associated with enhanced activation of fork head box o1 (foxo1). diabetologia; 53:378-388, 2010.

10. Cheng F, Shen Y, Mohanasundaram P, Lindstrom M, Ivaska J, Ny T, Eriksson JE. Vimentin coordinates fibroblast proliferation and keratinocyte differentiation in wound healing via TGF-beta-Slug signaling. Proc Natl Acad Sci USA 113, E4320-E4327, 2016.

11. Walker JL, Zhai N, Zhang L, Bleaken BM, Wolff I, Gerhart $\mathrm{J}$, George-Weinstein M, Menko AS. Unique precursors for the mesenchymal cells involved in injury response and fibrosis. Proc Natl Acad Sci USA 107, 13730-13735, 2010.

12. Menko AS, Bleaken BM, Libowitz AA, Zhang L, Stepp MA, Walker JL. A central role for vimentin in regulating repair function during healing of the lens epithelium. Mol Biol Cell 25, 776-790, 2014.

13. Barui A, Banerjee P, Das Rk, Basu SK, Dhara S, Chatterjee $\mathrm{J}$ : Immunohistochemical evaluation of p63, e-cadherin, collagen I and iii expression in lower limb wound healing under honey. Evid Based Complement alternat Med; 2011:239864, 2011

14. Martins VL, Caley M, O'Toole EA: Matrix metalloproteinases and epidermal wound repair. Cell Tissue Res;351:255-268, 2013.

15. Badr G: Camel whey protein enhances diabetic wound healing in streptozotocin-induced diabetic mouse model: The critical role of beta- defensing 1,2 and 3 . Lipids Health Dis;12:46, 2013.

16. Bermudez DM, Herdirich BJ, Xu J, Lind R, Beason DP, Mitchell ME, Soslowsky LJ, Liechty KW. Impaired biomechanical properties of diabetic skin implications in pathogenesis of diabetic wound complications. Am J Pathol; 178:2215-2223, 2011.

17. Yang C, Zhu P, Yan L, Chen L, Meng R, Lao G: Dynamic changes in matrix metalloproteinases 9 and tissue inhibitor of matrix metalloproteinases-1 during wound healing in diabetic rats. J Am Podiatr Med Assoc; 99:489-496, 2009.

18. Massague $\mathrm{J}$ and Gomis RR: The logic of tgfbeta signaling. FEBS Lett; 580:2811-2820, 2006.

19. Hotz B, Visekruna A, Buhr HJ, Hotz HG: Beyond epithelial to mesenchymal transition: A novel role for the transcription factor snail in inflammation and wound healing. J gastrointest Surg;14:388-397, 2010.

20. Wang X, Qian Y, Jin R, Wo Y, Chen J, Wang C, Wang D: Effects of trap-1 like protein (tlp) gene on collagen synthesis induced by tgf-beta/smad signaing in human dermal fibroblasts. Plos One;8:e55899, 2013.

21. Ramos AFN, De Miranda JL. Propolis: a review of its antiinflammatory and healing actions. J Venom Anim Toxins Incl Trop Dis; 13:697-700, 2007.

22. Araujo MAR, Libério SA, Guerra RNM, Ribeiro MNS, Nascimento FRF. Mechanisms of action underlying the anti-inflammatory and immunomodulatory effects of propolis: a brief review. Braz J Pharmacog; 22:208-219, 2011.

23. Ghisalberti EL. Propolis: a review. BeeWorld, vol.60, no. 2, pp.59-84, 1979. 
24. Scheller S, Stojko A, Szwarnowiecka I, Tustanowski $\mathrm{J}$ and Obuszko Z. Biological properties and clinical application of propolis. VI. Investigation of the influence of ethanol extracts of propolis (EEP) on cartilaginous tissue regeneration. Arzneimittel-Forschung, vol.27,no.11, pp.2138-2140,1977.

25. Bogdanov S. Propolis: composition, health, medicine: a review. Bee Prod Sci; 11:1-33, 2012.

26. Bohling MW, Henderson RA, Swaim SF, Kincaid SA and Wright JC. Cutaneous wound healing in the cat: a macroscopic description and comparison with cutaneous wound healing in the dog," Veterinary Surgery, vol. 33, no. 6, pp.579-587, 2004.

27. Phillips GD, Whitehead RA and Knighton DR. Initiation and pattern of angiogenesis in wound healing in the rat. American Journal of Anatomy, vol.192, no.3, pp.257-262, 1991.

28. Atiyeh BS, Dibo SA and Hayek SN. Wound cleansing, topical antiseptics and wound healing. International Wound Journal, vol.6, no.6, pp.420-430, 2009.

29. Cavalcante GM, Sousa de Paula RJ, Souza LP, Sousa FB, Mota MR and Alves AP. Experimental model of traumatic ulcer in the cheek mucosa of rats. Acta Cir. Bras.; 26(3):227-234, 2011.

30. Bankova VS, de Castro SL and Marcucci MC. Propolis: recent advances in chemistry and plant origin. Apidologie, vol. 31,no.1,pp.3-15,2000.

31. Kocot J, Kielczykowska M, Luchowska-Kocot D, Kurzepa J, Musik I. Antioxidant potential of propolis, bee pollen, and royal jelly: Possible medical application. Oxid Med Cell Longev 2018; 2018: 7074209.

32. Han S, Lee K, Yeo J, Kim W and Park K. Biological effects of treatment of an animal skin wound with honeybee (Apis melifera. L) venom. Journal of Plastic, Reconstructive and Aesthetic Surgery, 64(3), 2011.

33. Hashemipour MA, Ghasemi AR, Dogaheh MA and Torabi M. Effects of Locally and Systemically Applied n-3 Fatty Acid on Oral Ulcer Recovery Process in Rats. Wounds : A Compendium of Clinical Research and Practice, 24(9), 258-66, 2012.

34. Ramos A and Miranda Jd . Propolis: a review of its antiinflammatory and healing actions, J. Venom Anim. Toxins. 13 (4) :697-710, 2007.

35. Cho MS, Park WS, Jung WK, Qian Zj, Lee DS, Choi JS .Caffeic acid phenethyl ester promotes anti-inflammatory
MAPK and NF- $x$ B signaling in activated HMC-1 human mast cells, Pharm. Biol. 52 (7) 926-932, 2014.

36. Araujo MA, Libério SA, Guerra RN, Ribeiro MNS, Nascimento FR. Mechanisms of action underlying the anti-inflammatory and immunomodulatory effects of propolis: a brief review, Rev. Bras. Farmacogn. Braz. J. Pharmacogn. 22 (1) 208-219, 2012.

37. Martin LFT, Rocha EM, Garcia SB and Paula JS. Topical Brazilian propolis improves corneal wound healing and inflammation in rats following alkali burns. BMC Complementary and Alternative Medicine, 13, 337, 2013.

38. Fahim A, Ilyas MS, Jafari FH and Farzana F. Effect of carbonated drinks on wound healing of oral epithelium. Journal of Oral Biology and Craniofacial Research, 6(1), 50-54, 2016.

39. Jasprica I, Mornar A, Debeljak Ž, Smolčić-Bubalo A, Medić-Šarić M, Mayer L, Šverko V. In vivo study of propolis supplementation effects on antioxidative status and red blood cells. Journal of Ethnopharmacology, 110(3), 548-554, 2007.

40. Daleprane, JB and Abdalla DS. Emerging roles of propolis: Antioxidant, cardioprotective, and antiangiogenic actions. Evidence-Based Complementary and Alternative Medicine, 175135, 2013.

41. Rivera-Yáñez, N.; Rodríguez-Canales, M.; NietoYáñez, O.; Jiménez-Estrada, M.; Ibarra-Barajas, M.; Canales-Martínez, M.M.; Rodríguez-Monroy, M.A. Hypoglycaemic and antioxidant effects of propolis of Chihuahua in a model of experimental diabetes2018,

42. Berretta AA, Nascimento AP, Bueno PCP, Leite Vaz M M de OL and Marchetti JM .Propolis standardized extract (EPP-AF), an innovative chemically and biologically reproducible pharmaceutical compound for treating wounds. International Journal of Biological Sciences, 8(4), $512-521,2012$.

43. Noli $\mathrm{C}$ and Miolo A. The mast cell in wound healing, Vet. Dermatol. 12 (6) 303-313, 2001.

44. Ng MF. The role of mast cells in wound healing, Int. Wound J. 7 (1) 55-61, 2010.

45. K. Weller, K. Foitzik, R. Paus, W. Syska, M. Maurer, Mast cells are required for normal healing of skin wounds in mice, FASEB J. 20 (13) 2366-2368, 2006.

46. P.R. Barroso, R. Lopes-Rocha, E.M.F. Pereira, S.A. Marinho, J.L. de Miranda, N.L. Lima, et al., Effect of propolis on 
mast cells in wound healing, Inflammopharmacology 20 (5) 289-294, 2012.

47. M.S. Cho,W.S. Park, W.-K. Jung, Z.-j. Qian, D.-S. Lee, J.-S.Choi, et al., Caffeic acid phenethyl ester promotes anti-inflammatory effects by inhibiting MAPKandNF- $x \mathrm{~B}$ signaling in activated HMC-1 human mast cells, Pharm. Biol. 52 (7) 926-932, 2014.

48. M.A. Nader, Caffeic acid phenethyl ester attenuates IgE-induced immediate allergic reaction, Inflammopharmacology 21 (2) 169-176, 2013.

49. Mendez MG, Kojima S, Goldman RD: Vimentin induces changes in cell shape, motility, and adhesion during the epithelial to mesenchymal transition. FASEB J 24(6): 1838-1851, 2010.
50. Vuoriluoto K, et al.:Vimentin regulates EMT induction by Slug and oncogenic H-Ras and migration by governing Axl expression in breast cancer. Oncogene 30(12): 1436$1448,2011$.

51. Virtakoivu R, et al. : Vimentin-ERK signaling uncouples Slug gene regulatory function. Cancer Res 75(11):2349 2362, 2015.

52. Challa AA, Stefanovic B A novel role of vimentin filaments: Binding and stabilization of collagen mRNAs. Mol Cell Biol 31(18):3773-3789, 2011.

53. Cheng F, Shen Y, Mohanasundaram P, Lindstrom M, Ivaska J, Ny T, Eriksson JE. : Vimentin coordinates fibroblast proliferation and keratinocyte differentiation in wound healing via TGF-beta-Slug signaling. Proc Natl Acad Sci U S A 113:E4320-E4327, 2016. 